\title{
Penjadwalan Reservasi Instruktur Sertifikasi Berbasis Android di PKSTI Bandung
}

\author{
Tri Ramdhany ${ }^{1}$, Elis Silmi N. ${ }^{2}$, Marfy Alfarezye A. ${ }^{3}$ \\ ${ }^{1,2,3}$ Program Studi Sistem Informasi \\ 1,2,3 STMIK LPKIA Bandung, J1. Soekarno Hatta NO. 456 Bandung \\ Email : tri@1pkia.ac.id ${ }^{1}$, elis@fellow.lpkia.ac.id ${ }_{2}^{2}$ marfyal@fellow.lpkia.ac.id ${ }^{3}$
}

\begin{abstract}
ABSTRAK
Sertifikasi internasional pada saat ini sudah menjadi kebutuhan primer guna meningkatkan dan melatih skill yang dimiliki setiap individu baik karyawan maupun mahasiswa. Kebutuhan itulah yang membuat setiap instansi maupun universitas membutuhkan sebuah organinsasi yang menyelenggarakan sertifikasi internasional beserta instruktur yang dapat membimbing pelaksanaan ujian sertifikasi seperti yang diselenggarakan oleh lembaga Pusat Kajian Teknologi Informatika Bandung (PKSTI).

PKSTI sebagai Lembaga yang mengelola kegiatan pelatihan masih mengalami beberapa kendala diantaranya dalam menentukan instruktur yang sesuai dengan pelatihan yang akan di selengarakan selain itu sulitnya dalam memonitoring administrasi pelaksanaan pelatihan ditinjau dari jumlah kebutuhan instruktur, penjadwalan pelatihan, maupun evaluasi setelah pelatihan berlangsung. Atas dasar masalah yang terjadi maka diperlukan sebuah aplikasi yang mampu mempermudah pihak manajemen PKSTI dalam mengelola kegiatan pelatihan tersebut.

Platform android di pilih dalam membangun aplikasi tersebut dengan tujuan agar memudahkan akses pengguna pada aplikasi hal ini ditunjukan dengan banyaknya pengguna Smartphone berbasis android. Agar aplikasi yang dibangun sesuai kebutuhan bisnis dan dapat memberi solusi terhadap masalah maka pendekatan pengembangan perangkat lunak yang digunakan adalah prototype, karena metode ini memiliki iterasi pengujian aplikasi oleh pengguna sehingga kebutuhan pengguna dapat di fasilitasi dengan baik oleh pengembang aplikasi.
\end{abstract}

Kata Kunci: Penjadwalan, Sertifikasi, Android, Prototype

\section{ABSTRACT}

International certification has become a primary need to improve and train the skills possessed by each individual, both employees and students. It is this need that makes every institution and university need an organization that organizes international certifications along with instructors who can guide the implementation of certification exams such as those held by the Bandung Information Technology Study Center (PKSTI).

PKSTI as an institution that manages training activities still experiences several obstacles, including in determining the appropriate instructors for the training to be held, besides the difficulty in monitoring the administration of the training implementation in terms of the number of instructor needs, training scheduling, and evaluation after the training takes place. On the basis of the problems that occur, we need an application that is able to facilitate the PKSTI management in managing the training activities. 
The android platform was chosen in building the application with the aim of making it easier for users to access the application, this is indicated by the large number of Android-based Smartphone users. So that applications are built according to business needs and can provide solutions to problems, the software development approach used is a prototype, because this method has iterations of application testing by users so that user needs can be properly facilitated by application developers.

Keywords: Scheduling, Certification, android, Prototype

\section{PENDAHULUAN}

\subsection{Latar Belakang}

Pelatihan yang diselenggrakan oleh PKSTI sangat memerlukan pelatih atau instruktur untuk membantu dalam membimbing pelatihan. Bisa disebut instruktur adalah satu atau beberapa orang yang memandu dan mengajarkan hal yang menjadi bidangnya pada satu kumpulan pelatihan. Membuat kumpulan orang yang mengikuti pelatihan pada bidang yang dituju karena mereka mengajarkan dan memandunya dalam lingkungan lebih kecil sehingga lebih terfokus pada masing - masing individu.

Karena banyak sekali Intansi yang membutuhkan pelatihan untuk menunjang kemampuan mereka menghubungi PKSTI. PKSTI membutuhkan instruktur - instruktur berpengalaman dan dapat membantu di pelatihan yang diperlukan dengan menghubunginya. Tetapi PKSTI memakai media social secara personal sehingga tidak terlapor dengan baik. Dan dibutuhkan pengelolaan untuk mensinkronisasi jadwal pelatihan dan jadwal Instruktur.

Teknologi yang cocok pada era ini dan memecahkan masalah ini adalah dengan menggunakan smartphone Android. Karena masyarakat telah banyak menggunakan android termasuk PKSTI dan para instruktur pelatihan.

\subsection{Identifikasi Masalah}

Melalui pembahasan permasalahan di latar belakang dapat diambil masalah utama sebagai berikut :

1. Bagaimana menentukan kriteria instruktur yang akan ikut pelatihan?

2. Bagaimana menentukan jumlah instruktur yang dibutuhkan?

3. Bagimana melakukan penjadwalan instruktur?

4. Bagaimana manajemen Unit bisnis pelatihan dapat memonitoring dan mengevaluasi hasil pelatihan dan sertifikasi sehingga dapat mengambil keputusan lebih lanjut? 
5. Bagaimana membuat hasil pelatihan yang telah diikuti setiap instruktur?

\subsection{Tujuan}

Tujuan dari penyelesaian masalah ini adalah :

1. Menentukan kriteria instruktur yang akan ikut pelatihan dengan katagori sertifikasi

2. Menentukan jumlah instruktur yang dibutuhkan dari masing - masing pelatihan

3. Melakukan penjadwalan instruktur sesuai dengan aturan yang ditentukan

4. Manajemen Unit bisnis pelatihan dapat memonitoring dan mengevaluasi hasil pelatihan dan sertifikasi para intruktur

5. Membuat rekap hasil pelatihan yang telah diikuti setiap instruktur

\subsection{Ruang Lingkup}

Agar penulisan lebih terfokus dan terarah serta pembahasan yang dibahas tidak meluas, maka penulis membatasi ruang lingkup penelitian sebagai berikut :

1. Aplikasi ini tidak menangani masalah hasil dari sertifikasi yang di pegang pihak pemegang bisnis

2. Aplikasi ini tidak menangani masalah penggajian dan absensi

3. Aplikasi ini tidak menangani pembuatan materi pelatihan dan sertifikasi

\subsection{Metodologi}

\section{Pendekatan Penelitian}

Metode pengembangan sistem ini digunakan metode Prototype, metode ini memungkinkan pengguna melakukan pengujian terhadap working model yang merupakan gambaran awal dari software yang di bangun sehingga spesifikasi kebutuhan yang diinginkan pengguna dapat tersampaikan ke pengembang(Ramdhany \& Krisdiawan, 2017)

\section{Teknik Pengumpulan Data}

Teknik pengumpulan data yang dipergunakan dalam penelitian ini adalah:

1. Wawancara

Teknik ini digunakan untuk memperoleh informasi mengenai kebutuhan fungsional sistem yang akan di bangun berasal dari pengguna.

2. Studi Pustaka 
Studi pustaka ini dilakukan dengan tujuan memperoleh literatur dan dasar teori dari sistem yang akan di bangun

\section{LANDASAN TEORI}

\subsection{Penjadwalan}

Jadwal menurut kamus besar bahasa Indonesia adalah pembagian waktu berdasarkan rencana pengaturan urutan kerja, daftar atau tabel kegiatan atau rencana kegiatan dengan pembagian waktu pelaksanaan yang terperinci. Sedangkan pengertian penjadwalan adalah proses, cara, perbuatan menjadwalkan atau memasukkan ke dalam jadwal.(Kemendikbud, 2016)

\subsection{Sertifikasi Internasional}

Kebutuhan pasar global akan professional teknologi informasi yang teruji dan handal di butuhkan adanya bentuk sertifikasi terhadap keahlian bidang infomatika yang diakui secara internasional, oleh karena itu sertifikasi internasional adalah bentuk kredibilitas kompentensi seseorang yang telah diuji dan di dokumentasikan sehingga menunjukan profesionalitas keahlian seseorang di bidangnyan(Rifai et al., 2019)

\subsection{Android}

Android merupakan sebuah sistem operasi berbasis mobile yang biasanya digunakan di dalam smartphone. Android sendiri memiliki sifat open source yang dimana pengembang bisa mengembangkan berbagai aplikasi berbasis android baik dimodifikasi maupun di distribusikan kembali. Android juga memiliki komunitas pengembang aplikasi terbersar(Adhita, 2017).

Aplikasi android yang dikembangkan menerapkan pendekatan object oriented analysis and design (OOAD) pendekatan ini merupakan pendekatan analisis manipulasi objek-objek sistem dan subsistem sebagai kebutuhan dari fungsional sistem itu sendiri(Ramdhany, 2020). 


\section{Analisis dan Perancangan}

\subsection{Use Case Diagram}

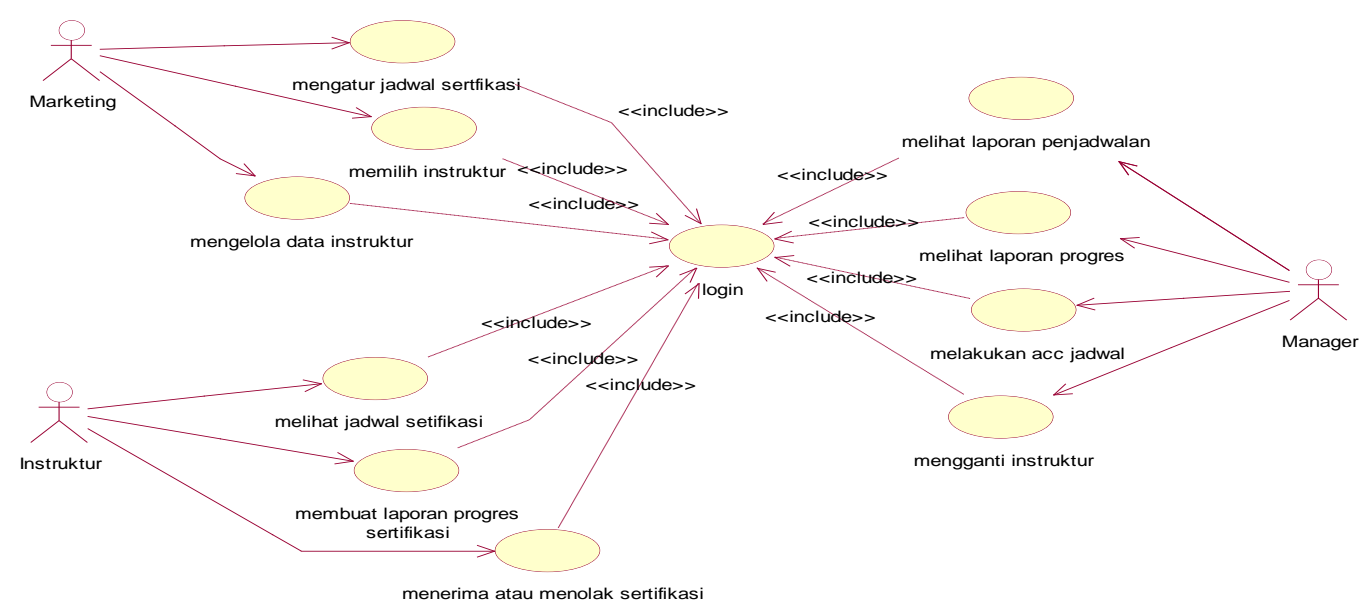

Gambar 1: Usecase Diagram

Proses penjadwalan instruktur sertifikasi internasional digambarkan dalam usecase model diagram dilakukan dengan tahapan berikut :

1. Marketing melakukan pendaftaran atau mengisi data instruktur yang akan mendaftar menjadi instruktur sertifikasi di PKSTI Bandung.

2. Marketing mengatur jadwal sertifikasi berdasarakan jadwal dari permintaan customer

3. Markketing melakukan pencarian instruktur sesuai dengan sertifikasi yang dipilih.

4. Setelah mengatur jadwal dan memilih instruktur, maka data penjadwalan akan terkirim ke instruktur yang dipilih dan manager di PKSTI untuk meminta persetujuan sertifikasi.

Proses penjadwalan pada instruktur dan laporan progress sertifikasi digambarkan pada usecase model diagram dilakukan dengan tahapan sebagai berikut :

1. Instruktur menyetujui penjadwalan sertifikasi internasional yang diberikan oleh marketing.

2. Instruktur melihat penjadwalan sertifikasi yang telah ditentukan.

3. Instruktur yang sedang melakukan sertifikasi dianjurkan untuk membuat laporan kemajuan sertifikasi yang akan dikirimkan ke manager PKSTI. 
Proses persetujuan penjadwalan sertifikasi, dan laporan penjadwalan pada manager digambarkan pada usecase model diagram dilakukan dengan tahapan sebagai berikut :

1. Manager menerima notifikasi penjadwalan sertifikasi untuk dilakukanya persetujuan sertifikasi

2. Tugas manager selanjutnya mengganti instruktur apabila instruktur yang telah direservasi tidak dapat melakukan sertifikasi atau adanya masalah pribadi.

3. Manager dapat melihat laporan dari instruktur dan laporan hasil penjadwalan sertifikasi

\subsection{Class Diagram}

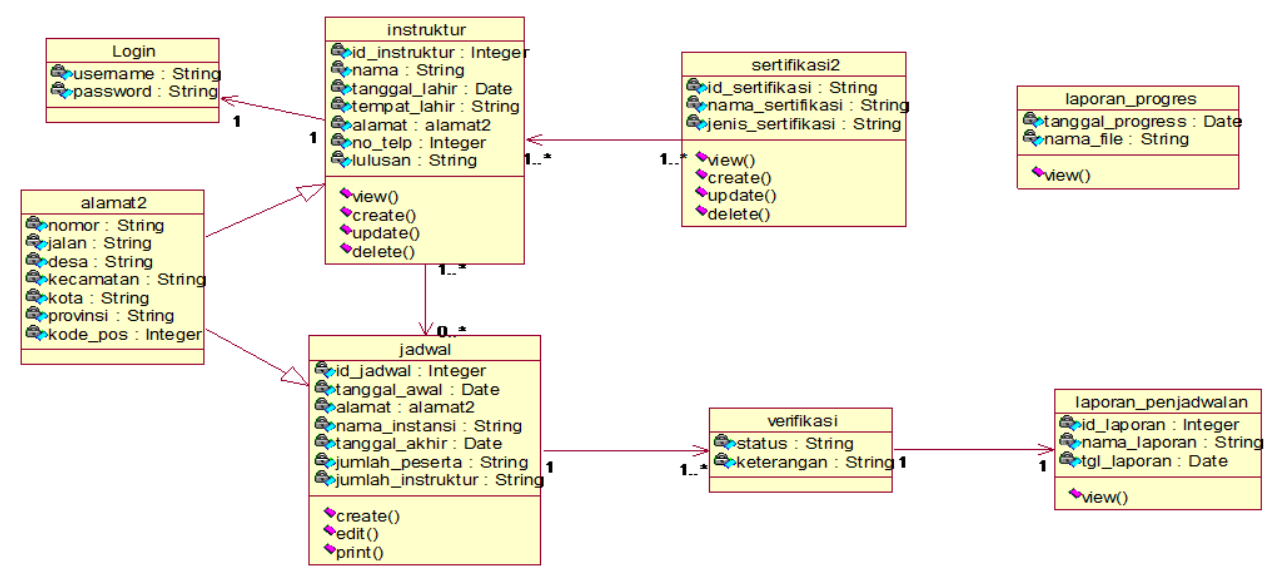

Gambar 2: Class Diagram

Terdapat 8 class yang akan digunakan dalam pembuatan perangkat lunak yaitu login, instruktur , jadwal , alamat, sertifikasi, laporan_progress, laporan_penjadwalan, dan verifikasi. 


\subsection{Perancangan Mockup}

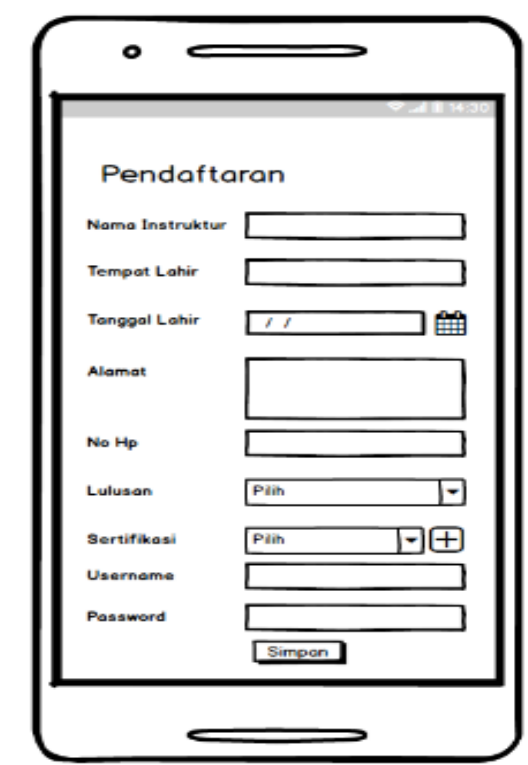

Gambar 3: Pendaftaran Instruktur

Layout ini digunakan sebagai form pendaftaran untuk instruktur yang diinputkan oleh bagian marketing

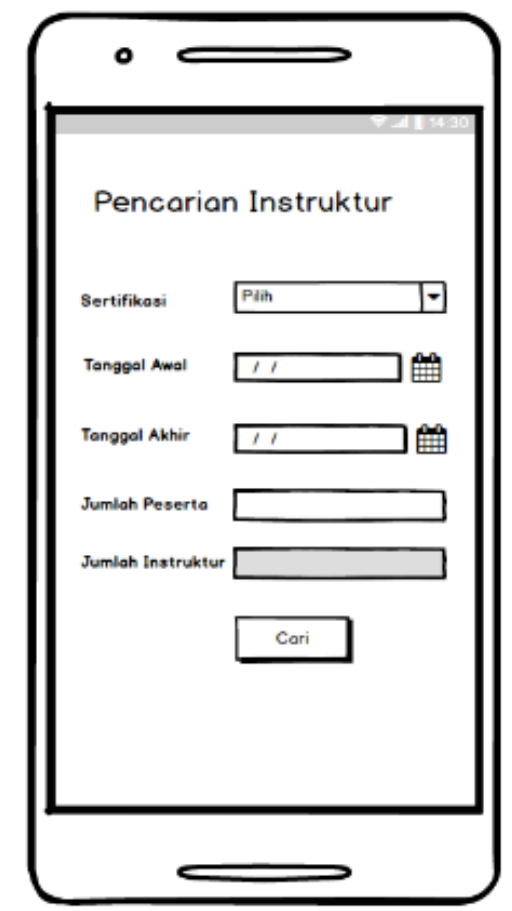

Gambar 4: Pencarian Instruktur 
Layout ini digunakan sebagai pencarian instruktur yang diinputkan oleh marketing. Setelah pihak instansi menghubungi bagian marketing maka bagian marketing akan mencarikan instruktur yang tepat sesuai dengan permintaan pihak instansi.

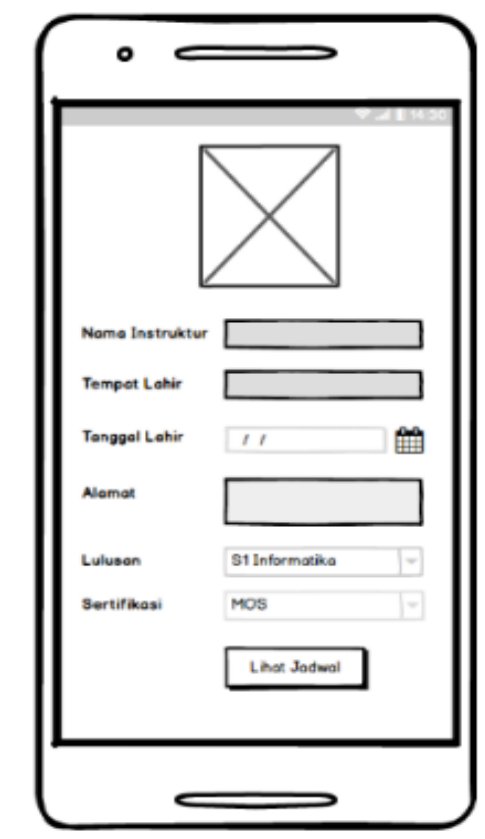

Gambar 5: Profil Instruktur

Layout ini digunakan sebagai tampilan untuk menampilkan profil dari instruktur

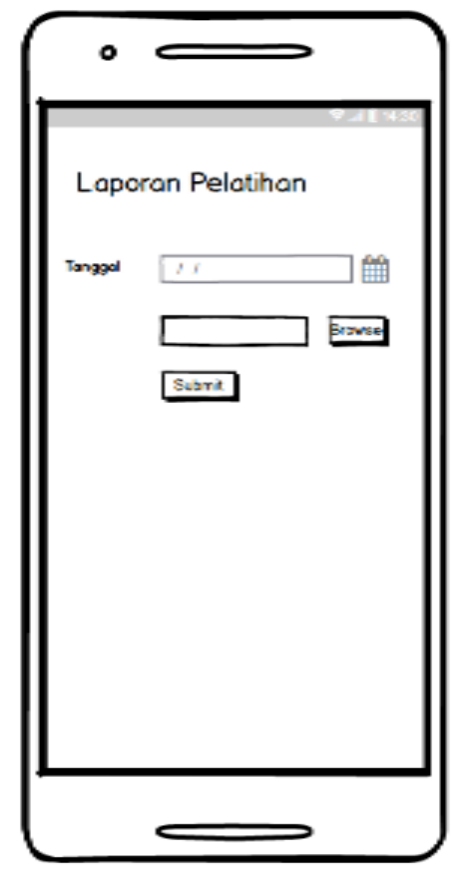

Gambar 6: Pencarian Jadwal 
Layout ini digunakan instruktur untuk mengetahui permintaan sertifikasi sesuai dengan pilihan dari pihak instansi dan pihak marketing.

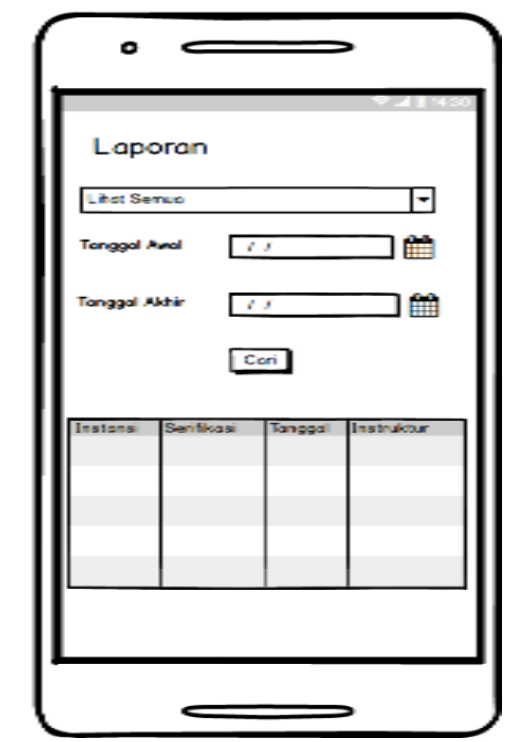

Gambar 7: Pencarian Laporan

Layout ini digunakan stakeholder untuk melihat laporan sertifikasi yang sudah dilaksanakan oleh para instruktur.

\section{IMPLEMENTASI}

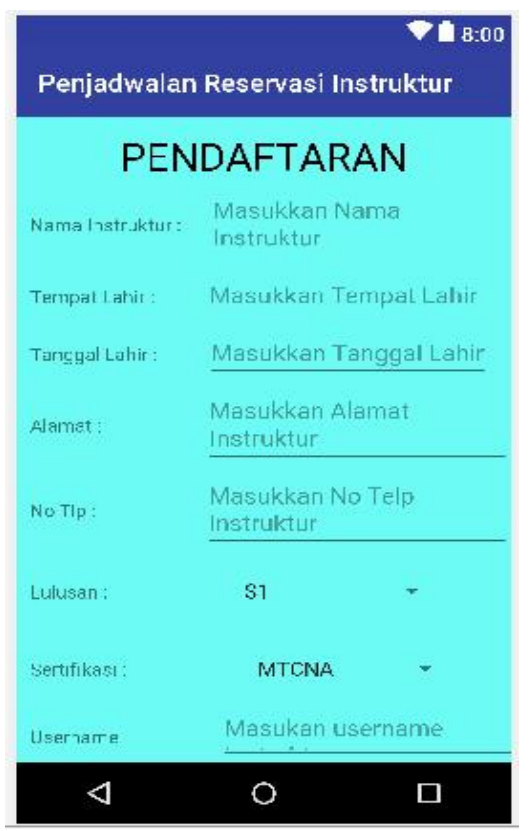

Gambar 8: Pendaftaran Instruktur 
Tampilan Pendaftaran Instruktur yang hanya bisa diakses oleh bagian marketing.

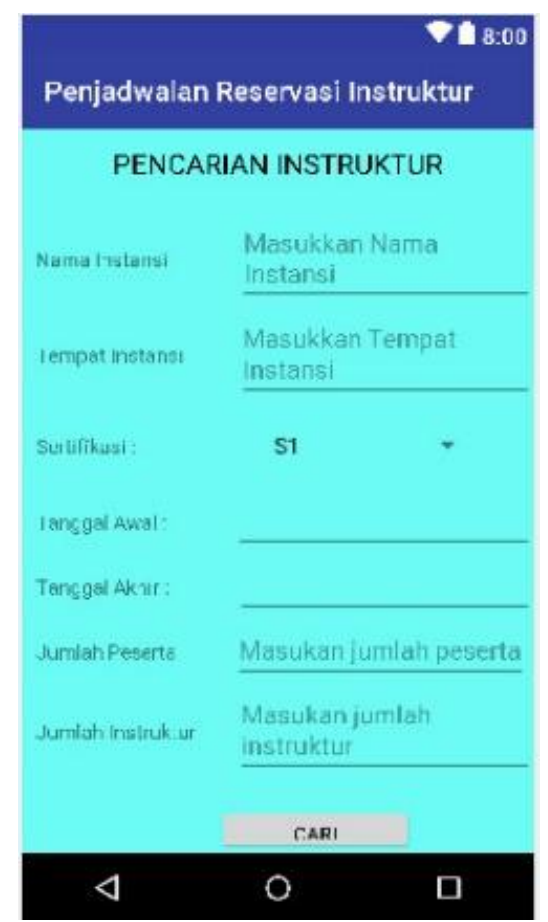

Gambar 9: Pencarian Instruktur

Tampilan Pencarian Instruktur yang hanya bisa diakses oleh bagian marketing.

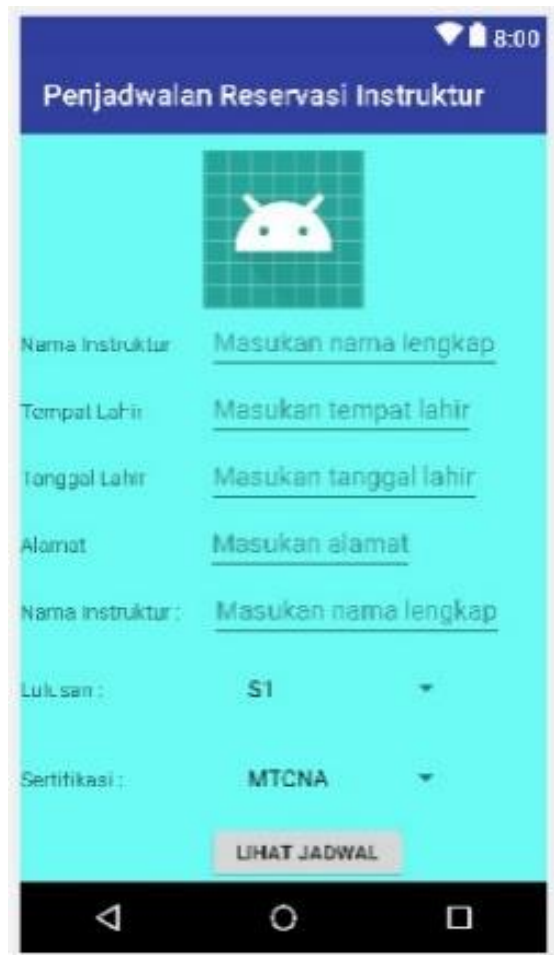

Gambar 10: Profil Instruktur 
Tampilan Profil Instruktur yang hanya bisa diakses oleh Instruktur.

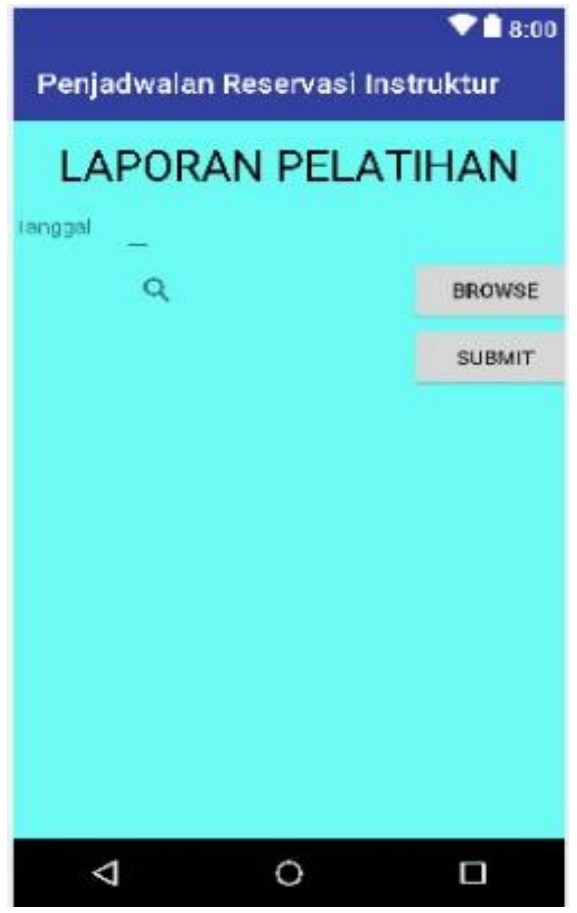

Gambar 11: Pencarian Instruktur

Tampilan Pencarian Jadwal yang hanya bisa diakses oleh Instruktur untuk mengetahui jadwal sertifikasi sesuai permintaan.

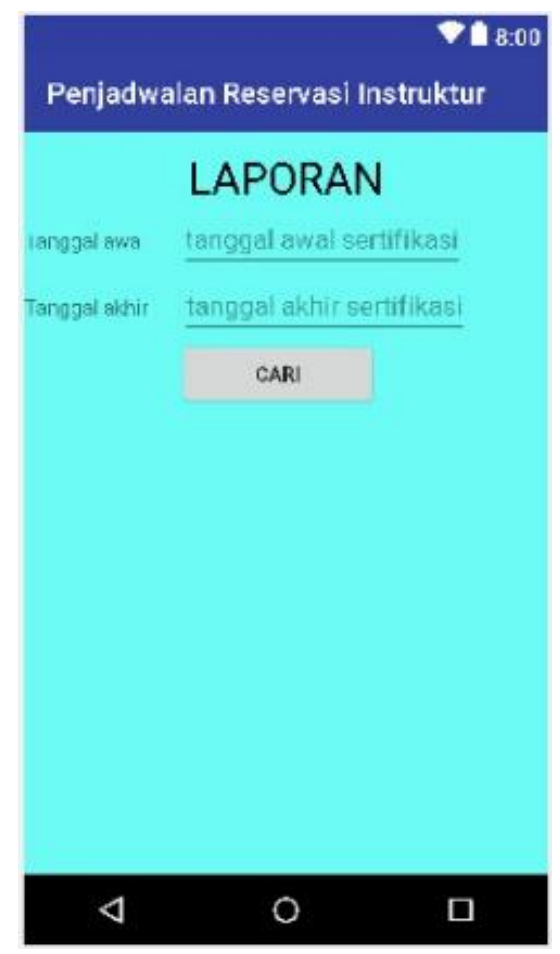

Gambar 12: Laporan Stakeholder 
Tampilan Pencarian Laporan Stakeholder yang hanya bisa diakses oleh Stakeholder untuk mengetahui sertifikasi yang sudah dilakukan oleh instruktur.

\section{SIMPULAN}

Penggunaan aplikasi berbasis android maka memudahkan pihak manajemen dalam mengakses informasi maupun monitoring kegiatan pelatihan hal ini disebabkan adanya fitur laporan pelatihan dengan memasukan jangka waktu pelatihan maka akan muncul informasi pelatihan yang sedang berjalan dan sudah selasai.

Fitur kelola data instruktur memudahkan manajemen untuk melakukan komunikasi dengan instruktur mengenai reservasi instruktur terhadap pelatihan yang akan diselenggarkan, menentukan kualifikasi instruktur berdasarkan kebutuhan pelatihan. Selain itu instruktur pun dimudahkan dalam memperoleh informasi mengenai jadwal pelatihan yang akan berlangsung sehingga persiapan yang dapat dilakukan oleh instruktur dapat dilakukan lebih baik lagi.

\section{DAFTAR PUSTAKA}

Adhita, R. (2017). Rancang Bangun Aplikasi Finding-Tutor Berbasis Android dan Penentuan Prioritas Seleksi Murid. Rancang Bangun Aplikasi Finding-Tutor Berbasis Android Dan Penentuan Prioritas Seleksi Murid, 1-173.

Kemendikbud. (2016). Kamus besar indonesia. Kemdikdbud. https://kbbi.kemdikbud.go.id/

Ramdhany, T. (2020). Perancangan Arsitektur Integrasi Sistem Informasi Menggunakan Metode Service Oriented Analysis And Design (SOAD) (Studi Kasus : Politeknik LPKIA Bandung) Tri. INFORMASI (Jurnal Informatika Dan Sistem Informasi), 12(1), 25-37.

Ramdhany, T., \& Krisdiawan, R. A. (2017). RANCANG BANGUNAPLIKASI PENGUKURAN KINERJAKEUANGAN PERUSAHAAN MENGGUNAKAN METODE ANALISIS RASIO KEUANGAN (Studi Kasus: Mitra Jaya Group Cabang Bandung). Cloud Information, I(ISSN 2527-5224), 29-36. https://journal.uniku.ac.id/index.php/cloudinformation/article/view/571/pdf

Rifai, M. F., Jatnika, H., \& Valentino, B. (2019). Penerapan Algoritma Naïve Bayes Pada Sistem Prediksi Tingkat Kelulusan Peserta Sertifikasi Microsoft Office Specialist (MOS). Petir, 12(2), 131-144. https://doi.org/10.33322/petir.v12i2.471 